\title{
Investigation of MQL-Employed Hard-Milling Process of S60C Steel Using Coated-Cermented Carbide Tools
}

\author{
Tran Minh Duc and Tran The Long \\ Department of Manufacturing Engineering, Faculty of Mechanical Engineering, Thai Nguyen University of Technology, Thai \\ Nguyen 250000, Vietnam
}

\begin{abstract}
The application of cutting fluids in machining brings out many benefits, but their use is accompanied by health and enviroment hazards. MQL (Minimum Quantity Lubricant) has become a preciously alternative solution for lubrication against dry machinning and flood cooling lubricant, and this is a step toward green machining. This paper presents a comprehensively experiemental study on investigation of MQL performance in hard milling of S60C steel for multiple responses, including surface quality, cutting forces and tool wear. Compared to dry milling, even-enhanced surfaces finish quality, 20\% less cutting force ( $\left.F_{t}\right)$ and almost $112 \%$ prolonged tool lifetime are achieved by using MQL with 5\% Emulsion in hard milling. In addition, this study compared the performances of MQL milling by using 5\% Emulsion to the peanut oil completely harmless to the enviroment. This encouraging result, therefore, reveals that the MQL-employed hard milling can enable significant improvement in productivity, product quality, and overall machining economy even after covering the additional cost of designing and implementing MQL system. Moreover, this study also shows the limitation of peanut oils employed in MQL and proposes the further research in novel additives to enhance the performance of cooling lubricant for vegetable oils.
\end{abstract}

Key words: MQL-employed hard milling, cutting force, dry milling, green machining.

\section{Introduction}

Of all hard machining processes for cutting workpiece with high hardness over 45HRC, hard milling is a high-performance machining process to provide good surface finish, high accuracy, high efficiency and cost-effectiveness. Thanks to a great innovation of cutting tool material in recent years, hard milling has been significantly developed and widely used to partly replace finish surface grinding process [1, 2].

Cermented carbides have been widely employed in hard milling, for example face milling when machining a plane surface. However, the traditional flood lubrication remains many applicable limitations. Because of extremely high temperature arised in the cutting zone under interrupted cuts, extreme tool wear due to thermal shock, resulting in sudden tool crack, have typically occurred when flood lubricating is used.

Corresponding author: Tran The Long, Ph.D., research fields: manufacturing engineering, and green machining.
Therefore, lubrication-free machining, or dry cutting, has widely been used in hard milling.

Environment-friendly is a fundamental advantage of dry cutting. However, this method producces a high cutting force, causing increased temperature in the cutting zone. Those phenomena result in low tool life because of extreme tool wear [2-4, 8]. Many alternatives have been investigated in order to mutally decrease friction and temperature in the cutting zone and improve cutting performance whilst maintain the environment-friendly condition. One of the alternatives, MQL (Minimum Quantity Lubricant) or near dry-cutting has become a promising solution for aforementioned cutting requirements. According to this lubricating method, a minimum or micro amount of cutting fluid is directly supplied into the cutting area as a form of mist mixed with highly pressurized compressed air through a nozzle. The benifical significance of cutting performace is therefore improved in terms of less cutting fliud required and 
then cost saving, small environmental influence, and more benefical impact on cooling the cutting tool.

Although MQL has been applied in a various range of machining process so far [1-8], there has been a lack of research of using MQL effectively in surface hard milling, particularly in the machining of S60C steel using economical cermented carbide tools and peanut oil based MQL hard milling as well. Therefore, the objective of this paper aims at an introduction of our recent success on applying MQL in hard milling by cermented carbide cutting inserts for S60C steel. The research investigates the cutting performance by using MQL against dry and flood milling and suggests relevant lubricants for hard milling. Experimental approach is carried out wherein the cutting performance is evaluated through surface quality, cutting force and tool life.

\section{Experimental Approach}

\subsection{Experiemental Devices}

Machine tool: VMC 85S machining center

Cutting tool: face milling of $\varnothing 80$ diameter with coated-cermented carbide inserts by LAMINA (APMT 1604 PDTR - Sweden)

Work piece: $100 \times 80 \times 50$ in geometry of S60C steel, hardness 42/45HRC

MQL system: NOGA nozzles, PT-0136 compressed air, pressure stabilization device, peanut oil, Emulsion $5 \%$ coolant

Measuring equipments: Kistler quartz three-component dynamometer (9257BA), SJ-201 Mitutoyo for surface roughness, TM-1000 optical microscope

\subsection{Cutting Parameters}

Cutting velocity $v=100 \mathrm{~m} / \mathrm{min}$; feed rate $f=80$ $\mathrm{mm} / \mathrm{min}$; width of cut $B=0.2 \mathrm{~mm}$ and depth of cut $d=$ $0.2 \mathrm{~mm}$.

Fluid conditions: air pressure $P=6$ bar; fluid flow rate $Q=0.23 / 0.25 \mathrm{~mL} / \mathrm{min}$.

The cutting fluid is directed into the tool flanks.

\subsection{Design for Experiments}

Experiments with three different methods are carried out, including dry cutting, MQL cutting with peanut oil and Emulsion fraction 5\%. For each experiment, cutting forces, surface roughness, and flank wear are measured after every $12 \mathrm{~min}$, i.e., 10 cuts. In order to evaluate the effectiveness of MQL on machinability, the force component $\mathrm{F}_{\mathrm{t}}$ (tangential force) mainly affecting to chip formation is concerned and online-measured by using Kistler quartz three-component dynamometer (9257BA), data acquisition system A/D DQA N16210 (made by National instruments, USA), and DASYlab 10.0 software (shown in Figs. 1 and 2). The surface roughness $(\mathrm{Ra})$ is measured three times by SJ-201 Mitutoyo and then taken of mean values with cut off length $0.8 \mathrm{~mm}$ for dry cutting and $0.25 \mathrm{~mm}$ for MQL cutting. The flank wear on cutting insert is evaluated through TM-1000 optical microscope.

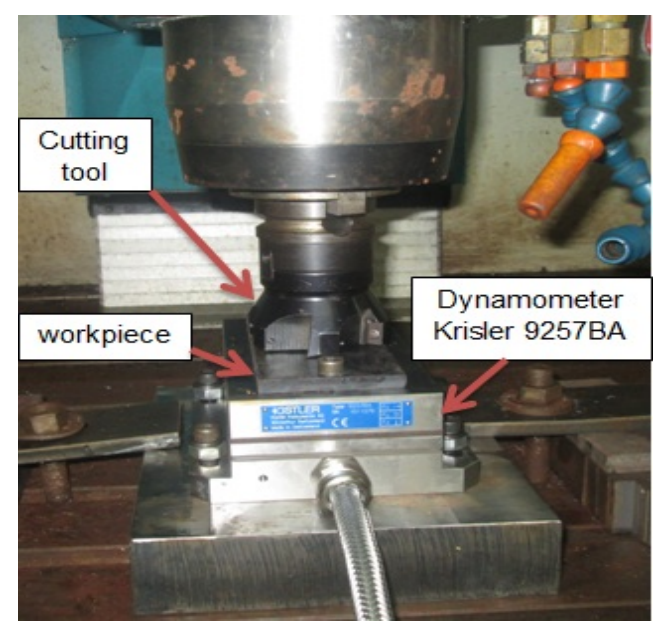

Fig. 1 Experiment setup.

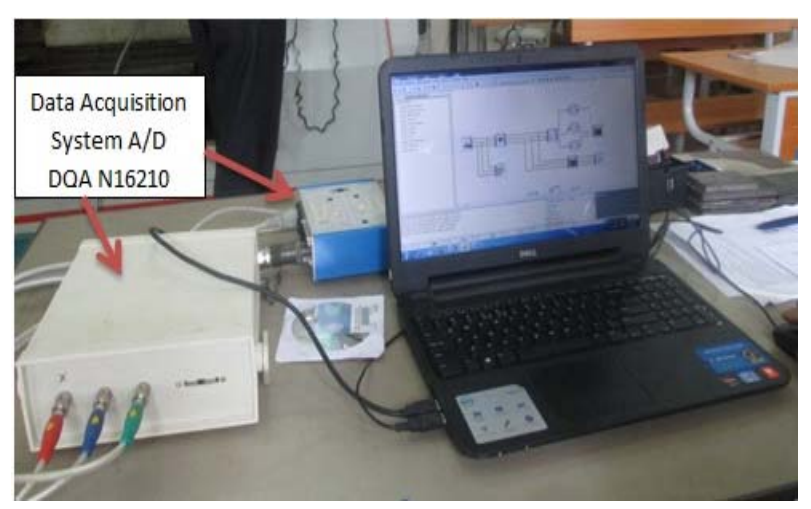

Fig. 2 Data acquisition system with computer. 


\section{Results and Discussion}

\subsection{Results}

The investigating responses, including roughness $\mathrm{Ra}$, cutting force $F_{t}$ and tool wear on flank which depends on machining time are described in Figs. 3-5. In addition, Fig. 6 presents the tool life of the cutting inserts at different cooling methods with respect to the tool life criteria of $0.4 \mathrm{~mm}$. The SEM illustration of wear on flank after 36 min machining is shown in Fig. 7.

\subsection{Discussion}

3.2.1 Comparison of Surafce Quality and Cutting Force among Different Cooling Methods

As clearly seen in Figs. 3-5, using MQL with Emulsion 5\% provides the best cutting conditions for all investigated responses. In comparison to dry cutting, MQL with Emulsion 5\% results in a 40\% smaller roughness $\left(R_{a}\right)$, while cutting force $F_{t}$ is $20 \%$ smaller. In contrast, the application of MQL with peanut oil brings the worst cutting condition with 100\% higher surface roughness $\left(\mathrm{R}_{\mathrm{a}}\right)$ and $22 \%$ higher cutting force $\mathrm{F}_{\mathrm{t}}$ compared to dry cutting.

\subsubsection{Analysis of Tool Wear and Tool Life}

The analysis of tool wear on flank was carried out after $36 \mathrm{~min}$, which is in the range of normal wear. It can be observed in Fig. 7 that wear occurs on both flank

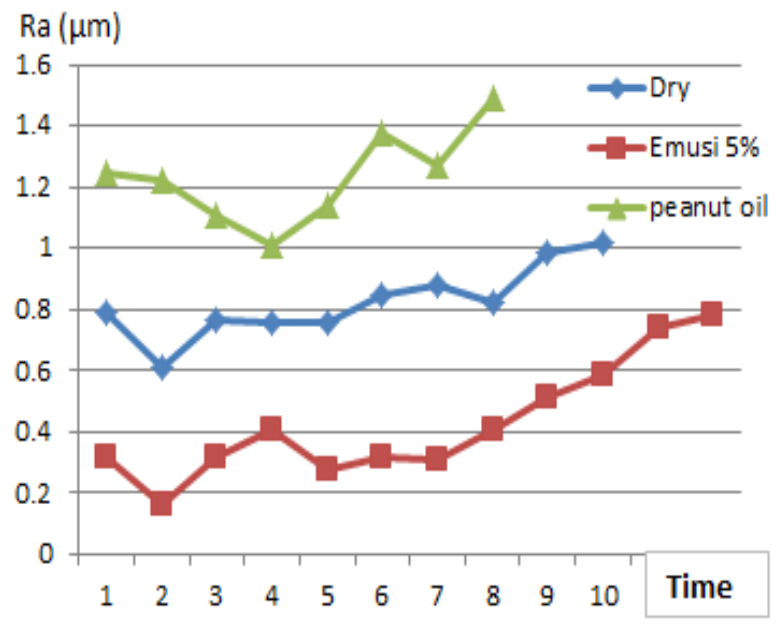

Fig. 3 Roughness Ra depending on cooling methods and machining time.

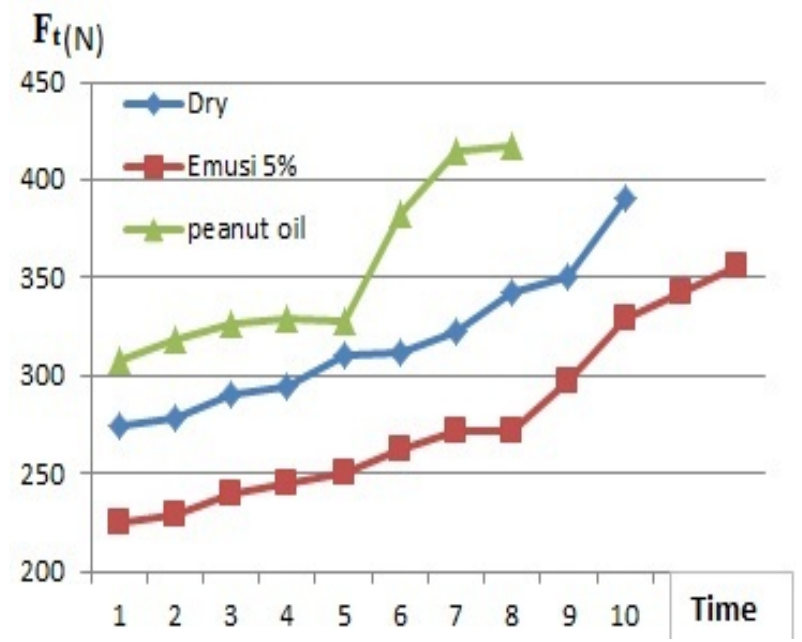

Fig. 4 Cutting force $F_{t}$ depending on cooling methods and machining time.

\section{Tool wear VB (mm)}

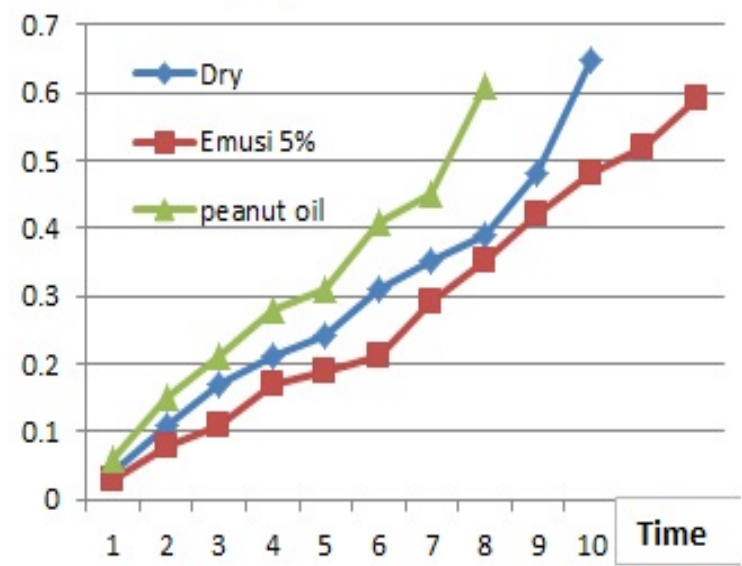

Fig. 5 Wear on flank depending on cooling methods and machining time.

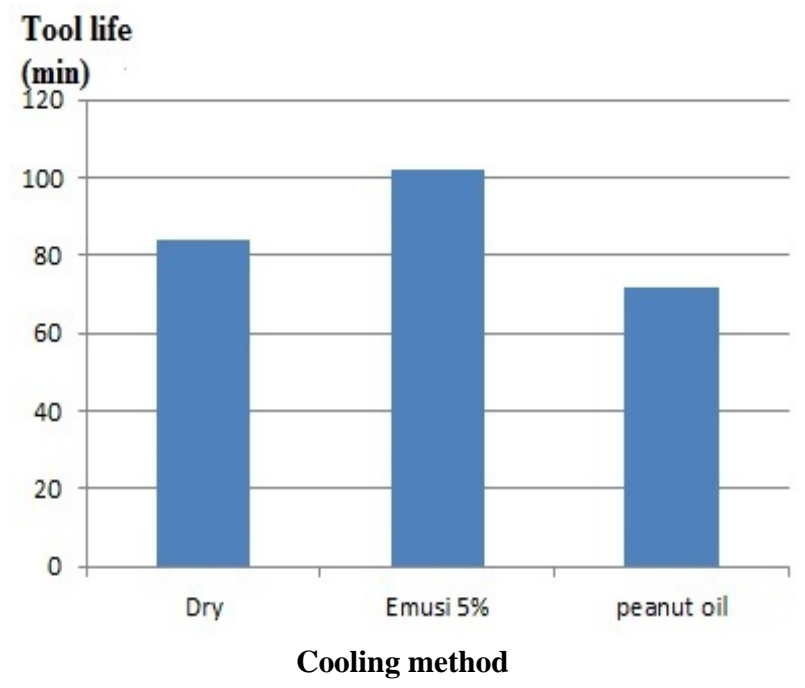

Fig. 6 Comparison of tool life for different cooling methods. 


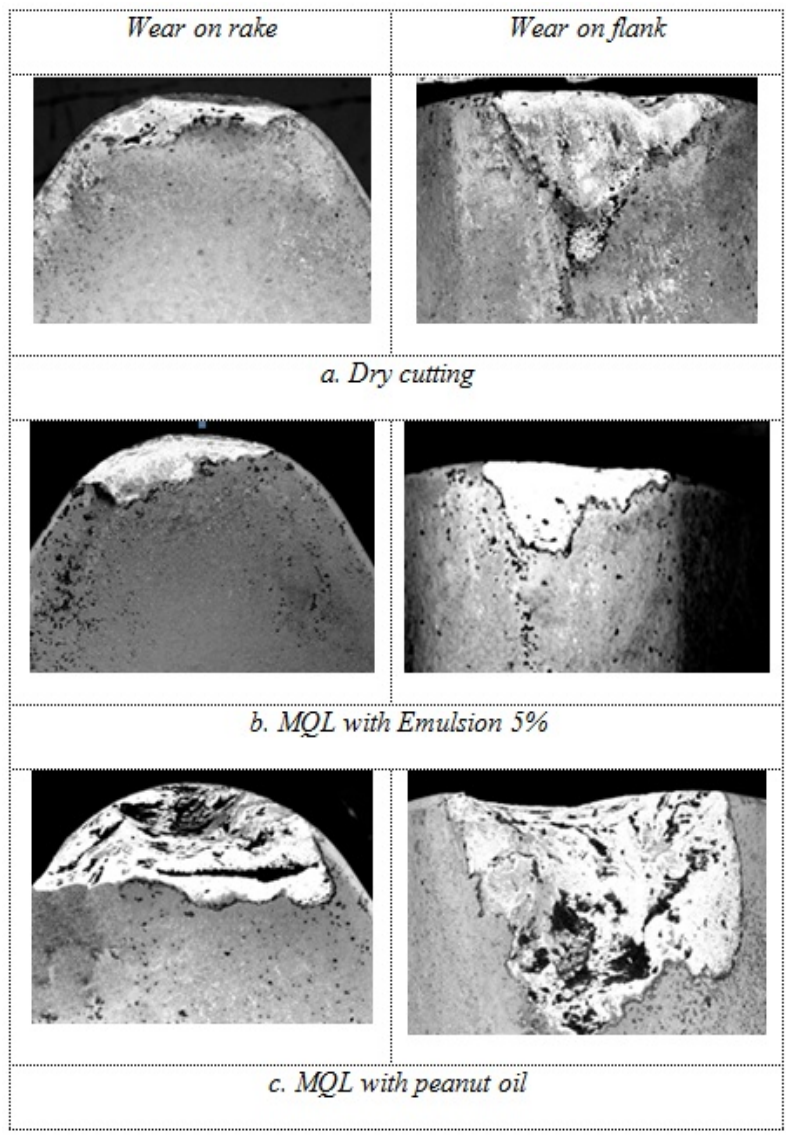

Fig. 7 Tool wear on rake and flank surface of cutting inserts.

and rake near the major cutting edge. As seen in Fig. 7, there is no evidence of chip sliding onto rake face, while wear on flank face is mainly occurred near the cutting edge. This observation can be explained by the high hardness of the workpiece so that elastic and plastic deformations are very small. It means friction between tool and workpiece mainly occurs at the major cutting edge and at the area near the cutting edge; therefore extreme wear happens in those areas. Moreover, due to a small depth of cut, thin chips are generated so that very little chips slide on the rake face; hence, there is almost no wear on the tool rake. Those observations of hard machining are very distinguished when compared to the machining processes for soft workpiece before heat treatment. Similar observations have been reported in previous research [1, 2, 4, 5].

Compared to dry cutting, less wear is found when using MQL with Emulsion 5\% while higher wear was occurred when using MQL with vegetable oil. Also, the result of tool wear phenomena carried out by this research for dry cutting is comparable to previous research [1-5] (Fig. 7a). The observation of milling using MQL with Emulsion 5\% shows that tool wear due to corrosion is much less than oserved in dry milling (Fig. 7b). This advantage is explained by the formation of thin liquid film generated on the interface of cutting tool and workpiece, which results in a reduction of tool wear and thus increase of tool life. A further comprehensive analysis should be investigated to evaluate properties and benifical contributions of this thin film on tool wear. On the contrary, there is no evidence of this film yet burning spots on the surface of tool when using MQL with peanut oil (Fig. 7c). This burning evidence shows that tool wear is mainly due to adhesion under high friction and temperature; therefore continuous melt chips adhered onto the tool faces and cause a much increase of wear and then decrease of tool life.

A similar finding is observed at the prolonged machining time near the end of tool life. Thereofore, the authors choose a critical depth of $0.4 \mathrm{~mm}$ for flank wear as a criterion for the analysis of tool life among different cooling methods. Fig. 6 shows that while tool life of cutting inserts when using MQL with peanut oil is only $75 \%$ in compared to dry cutting, the tool life by using MQL with Emulsion 5\% increases 112\% compared to dry cutting.

\subsubsection{Discussions}

According to above analysis, it is clearly agreed that using MQL with Emulsion 5\% provides the best cutting conditions, i.e., better surface quality, low cutting force and then longer tool service; however, the performance of cooling lubricant is less than other methods, as mentioned in previous reports [5-8]. This can be due to the frequent changes of distance between the nozzle tips and cutting inserts in face milling so that level of cutting fluid penetration into the cutting zone is reduced. Furthermore, the degree of thin film formation higly depends on the cutting speed during 
milling. A deep study on the degree of thin film formation by using MQL with Emulsion needs to be carried out and a determination of optimum cutting speed is required; the novel additives should be added to peanut oil in order to enhance its cooling lubricant performance. However, those are beyond the scope of this research, and these further studies will be carried out to bring out the promising results for MQL-employed hard machining in practice.

It is an interesting finding that the performance of MQL cooling method with peanut oil is less than that with Emulsion 5\%. This is the distinguished observation for the case of hard milling with using MQL compared to other machining processes for lower hardness such as turning, drilling or milling and hard turning [4-8]. Reasonable explanation is because of high viscous property of peanut oil, low mist generation and less penetration into the cutting zone; therefore it may be a main reason of not producing a thin film liquid on the tool surface; hence, the performance of lubrication is less. Also, it is important to argue that under high temperature in the cutting zone, the high boiling yet low burning temperatures of the peanut oil mainly cause burning spots on the surface of tools, leading higher temperature at the cutting zone, increasing adhesion on cutting inserts which definitely influences on the cutting performance.

\section{Conclusions}

This research has successfully applied MQL to hard milling with cermented carbide cutting inserts, wherein both surface quality and tool wear can be improved compared with the case of dry milling. Moreover, it can be seen that the selection of cutting fluid is very important for most of the machining processes. The results have demonstrated that using MQL with Emulsion 5\% in hard mill can much increase the cutting performance, in comparison of dry milling and peanut oil-based MQL milling.

The degree of wear on tools can be varied by using different cutting fluid and cooling methods; however, extreme wear mainly occurs at the areas near the major cutting edge during surface hard milling. This is the distinguished property of hard milling over other cutting processes. This understanding significantly guides further research on the decrease of tool wear, increase of surface quality, tool life and cutting performance and explores the new appropiate addtives for vegetable oils in order to enhance the performace of cooling lubricant in MQL-employed hard machining while remanining their characteristics of friendly environment .

\section{References}

[1] Liao, Y. S., and Lin, H. M. 2006. "Mechanism of Minimum Quantity Lubrication in High-Speed Milling of Hardened Steel.” International Journal of Machine Tools \& Manufacture 47: 1660-6.

[2] Liao, Y. S., Lin, H. M., and Chen, Y. C. 2007. "Feasibility Study of the Minimum Quantity Lubrication in High-Speed End Milling of NAK80 Hardened Steel by Coated Carbide Tool.” International Journal of Machine Tools \& Manufacture 47: 1660-6.

[3] Dhar, N. R., Islam, S., and Kamruzzaman, M. 2007. "Effect of MQL (Minimum Quantity Lubrication) on Tool Wear, Surface Roughness and Dimennsional Deviation in Turning AISI-4340 Steel.” G.U. Journal of Science 20: 23-32.

[4] Le, T.-S., Tran, M.-D., Nguyen, D.-B., and Nguyen, V.-C. 2013. "An Investigation on Effect of Characteristics of the Made in Vietnam Peanut oil MQL on Tool Life in Hard Turning 9CrSi Steel.” International journal of Machining and Machinability of Materials 13: 428-38.

[5] Truong, D. X., and Duc, T. M. 2013. "Effect of Cutting Condition on Tool Wear and Surface Roughness during Machining of Inconel 718.” International Journal of Advanced Engineering Technology 4: 108-12.

[6] Kang, M. C., Kim, K. H., and Shin, S. H. 2008. "Effect of the Minimum Quantity Lubrication in High-Speed End-Milling of AISI D2 Cold-Worked Die Steel (62 HRC) by Coated Carbide Tools.” Surf. Coat. Technol 202: 5621-4.

[7] Dhar, N. R., Ahmed, M. T., and Islam, S. 2007. “An Experimental Investigation on Effect of Minimum Quantity Lubrication in Machining AISI 1040 Steel.” Int. J. Mach. Tools Manuf. 47: 748-53.

[8] Pi, V. N., and Duc, T. M. 2010. "A Study on Multi-objective Optimization of Abrasive Blasting Systems.” Advanced Materials Research 126: 29-34. 